\title{
Será que o Direito é um Fenômeno Natural? Uma Crítica da Posição de Pontes de Miranda
}

\author{
Günther Maluschke \\ Doutor em Filosofia pela Universidade de Bonn. Livre- \\ docente pela Universidade de Tübingen (Alemanha). \\ maluschke@gmail.com
}

Sumário: Introdução. 1. O cientificismo de Pontes Miranda e seus problemas. 2. Problemas do método indutivo. Conclusão.

Resumo: A temática deste artigo é um exame crítico da tese da "Naturalidade do Fenômeno Jurídico" de Pontes de Miranda assim como uma refutação do método indutivo defendido por este autor, mas não aceito por Einstein como método adequado das ciências. Em contraste ao cientificismo de Pontes de Miranda pretende-se mostrar a superioridade de uma "sociologia compreensiva" no sentido de Max Weber.

Palavras-chave" Natureza. Naturalidade. Cientificismo. Método indutivo. Sociologia compreensiva.

\section{NTRODUÇÃO}

Na abertura do V Encontro de Iniciação à Pesquisa, no dia 27 de maio de 2009, proferi, na Faculdade 7 de Setembro, em Fortaleza, uma conferência com o título Bioética e Biodireito: Aspectos e Controvérsias (Maluschke, 2009). Nesta conferência, defendi, entre outras coisas, a tese de que tanto normas morais quanto jurídicas são invenções humanas, invenções necessárias para a sobrevivência da humanidade e para o nosso bem-estar. Somos nós que impomos nossos padrões à natureza, introduzindo assim a moral e o direito no mundo natural, que, em si nem é moral nem imoral, nem justo nem injusto.

Ciências descrevem e explicam os fenômenos e regularidades do mundo. Normas morais e jurídicas não são fenômenos e regularidades do mundo natural; são criações culturais; são fenômenos e regularidades particulares (não universais) do 
mundo cultural. O homem é por natureza um ser cultural; o resultado de suas atividades culturais é a natureza transformada em paisagem cultural. A cultura é, de certo modo, a segunda natureza do homem, sua maneira de se instalar no mundo.

No entanto, não existe - conforme a natureza propriamente dita - uma única "segunda natureza". Entende-se por cultura o modo de viver de um povo ou de uma nação, incluindo atitudes, crenças, valores e normas, artes, ciências, modos de pensamentos e de ação. Há várias culturas e, em conformidade com isto, uma pluralidade de éticas praticadas e de sistemas jurídicos. Não podemos negar o simples fato de que aquilo que é considerado verdadeiro, legítimo, valorizado, justo ou apreciado em um sistema social nem sempre o é em outro. Além disso, pode-se constatar que no mundo globalizado hoje em dia dentro da mesma cultura há opiniões morais heterogêneas, influenciadas por diferentes religiões, ideologias e concepções do mundo. Esta heterogeneidade de opiniões normativas é um indício de que o estudo de questões de interesse vital como a diferença entre o bem e o mal, o justo e o injusto, não pode ter uma pretensão à objetividade comparável com o conhecimento das ciências da Física, Química, Biologia, Matemática etc.

Baseando-me nestas ideias analisei, naquela conferência de 27 de maio de 2009, uma série de incertezas morais que são a principal razão pela qual se ocasionou a formação das duas disciplinas relativamente novas: a Bioética e o Biodireito.

Depois da conferência, o professor Agerson Tabosa me avisou que a posição por mim defendida contrastava absolutamente com a ideia da "Naturalidade do Fenômeno Jurídico" de Pontes de Miranda. Esta informação motivou a minha curiosidade por Pontes de Miranda, pois quis saber se as ideias e argumentos dele podiam me convencer e me obrigar a abandonar meus erros. No final, porém, a leitura levou-me a desenvolver uma crítica à posição de Pontes de Miranda, que apresento neste artigo.

\section{CIENTIFICISMO DE PONTES DE MIRANDA E SEUS PROBLEMAS}

Pontes de Miranda era, com certeza, um sábio universal, perito de Matemática, Lógica, Física, Química, Biologia; e sua imponente erudição manifesta-se, sobretudo, nas suas numerosas e grandes obras de Direito. No verso da capa do livro do professor Agerson Tabosa, Sociologia Geral e Jurídica (2005), encontra-se o seguinte citado de Pontes de Miranda (1983, p. 16):

No Direito, se queremos estudá-lo cientificamente como ramo positivo do conhecimento, quase todas as ciências são convocadas pelos cientistas. A extrema complexidade dos fenômenos implica a diversidade do saber. As matemáticas, a geometria, a física e a química, a biologia, a geologia, a zoologia e a botânica, a climatologia, a antropologia e a etnografia, a economia política e tantas outras constituem manan- 
ciais em que o sábio da ciência jurídica bebe o que lhe é mister. Nas portas das escolas de direito devia estar escrito: aqui não entrará quem não for sociólogo. E o sociólogo supõe o matemático, o físico, o biólogo. É flor de cultura.

Esta declaração soa como o anúncio de um projeto extremamente ambicioso, e afirmativas com este teor são bem típicas na obra de Pontes de Miranda. De fato, a objeção de que este programa é exigente demais e ultrapassa as capacidades científicas e profissionais da grande maioria dos "sábios da ciência jurídica" é, com certeza, pertinente, mas não atinge o conteúdo da ideia do autor. É possível que o Direito seja uma disciplina de extrema complexidade, e talvez muitos juristas não tenham a competência de cumprir adequadamente as tarefas de sua profissão. Pontes de Miranda critica severamente juristas que simplesmente identificam o Direito com as leis escritas nos códigos jurídicos.

Os verdadeiros problemas são os seguintes: como é possível utilizar adequadamente a multiplicidade dos conhecimentos específicos para explicar e compreender a extrema complexidade dos fenômenos na área do Direito? Como se orientar no vasto campo do saber com suas grandiosas descobertas e suas controvérsias sem fim; como se desviar do perigo de se perder em becos sem saída; como escolher os conhecimentos relevantes para a solução dos problemas em questão e não se obstinar em conhecimentos esotéricos e inúteis? Como se pode transformar a diversidade do saber em saber lógica e sistematicamente organizado? E como se pode justificar - e eis aí a nossa questão principal - que o fenômeno jurídico é um fenômeno natural?

Os especialistas em Pontes de Miranda podem oferecer uma primeira resposta: ele parte do princípio da unidade das ciências; defende a interdisciplinaridade, com o intuito de que pela colaboração das várias disciplinas na análise das relações sociais podem-se descobrir o Direito e sua eficácia. Por isso também se compreende a posição de destaque da Sociologia, pois é nas relações sociais, e não nos códigos jurídicos, que se revela o Direito. O método utilizado por Pontes de Miranda é o método indutivoexperimental, segundo ele o método único, exclusivo, na pesquisa científica, com grande sucesso utilizado nas ciências naturais.

Esta resposta não é satisfatória. Considerar o método indutivo como método por excelência da pesquisa científica é problemático. Nem mesmo o próprio Pontes de Miranda é consequente na aplicação desse método. Mostraremos que uma série de seus argumentos epistemologicamente relevantes não se fundamentam no método indutivo. E a identidade do método utilizado nas ciências naturais e no Direito - mesmo se for aceita essa tese duvidosa - não justifica a naturalidade do fenômeno jurídico. No entanto, antes de elaborar esta crítica central mais detalhadamente, deve-se analisar a argumentação de Pontes de Miranda. 
A essência de seu argumento manifesta-se em duas proposições: "Há em toda a comunidade, em todos os corpos sociais, certa virtude de organização intrínseca para a qual somente existe uma explicação e um processo: o Direito.” (Pontes de Miranda, 2000, t. I, p.114). Esta ideia se completa por outra afirmação: "Onde há espaço social há Direito, como onde há espaço atmosférico há corpos sólidos, líquidos ou fluidos que o ocupem." (Pontes de Miranda, 2000, t. I, p. 116).

É a universalidade e ubiquidade do Direito nas "comunidades", nos "corpos sociais", nas "relações sociais" que, segundo Pontes de Miranda, caracterizam sua naturalidade. Entretanto, pela comparação entre o "espaço social", para cuja constituição o Direito é imprescindível, e o "espaço atmosférico", que inclui corpos sólidos, líquidos e fluidos, não se pode justificar a naturalidade do Direito. Em caso de guerra civil, por exemplo, o espaço atmosférico se mantém inalterado: a vida pública, ao contrário, transforma-se em estado sem direito, em relação social no qual o Direito se esvazia (transforma-se, neste caso, de acordo com Kant, em status justitia vacuus), pois as instituições - criações humanas, não naturais - que, nos tempos de paz, mantêm a ordem pública, não funcionam mais; o Direito, a "virtude de organização intrínseca" da comunidade, perde sua força. Se, porém, pode haver tal estado de exceção, uma sociedade sem direito, situação provocada por atividades bélicas, ações antissociais, então o Direito não pode ser um elemento "natural" das relações sociais.

O caso hipotético de uma guerra civil funciona aqui como teste no qual a suposição da naturalidade do fenômeno jurídico devia se corroborar. Todavia, o resultado desse teste é negativo. Pela guerra civil pode-se fazer desaparecer o Direito, elemento constitutivo da ordem social. As regularidades naturais, contudo, são inalteráveis. Ninguém pode suspender as leis naturais; essas regularidades não incluem circunstâncias excepcionais. Pontes de Miranda nivela a diferença entre regularidades sociais, regularidades particulares, apesar de serem predominantes na maioria das sociedades, por um lado, e regularidades naturais, por outro lado, que, de fato, são universais. A ideia incorreta da naturalidade do fenômeno jurídico é consequência desse nivelamento errôneo.

Não se pode negar que, no capítulo indicado, Pontes de Miranda apresenta ideias e argumentos plausíveis, por exemplo, a tese da primazia do Direito em relação ao Estado. Segundo Pontes de Miranda "à vida humana não é essencial o Estado; o que é imprescindível às organizações humanas, às sociedades, é o ritmo, a ordem." (2000, tomo I, p. 114). Para se estabelecer e se manter a ordem o Direito é imprescindível. Todavia, o Direito como fator de ordem na sociedade não é produto da natureza; ao contrário, é campo de eficiência da intencionalidade, do querer e da ação do homem como ser social e político.

Não se pode dizer que este aspecto esteja totalmente ausente no pensamento de Pontes de Miranda, mas, apresentando-se na forma de um naturalismo cientificista, a 
relevância das atividades políticas e sociais permanece fora da consideração. Atividades humanas são interpretadas como "processos". Afirma Pontes de Miranda: "O que há de imutável no Direito é o fenômeno, o processo social de adaptação...” (2000, t. I, p. 117). Ele compreende esse processo como "constante da harmonia social" e compara com “a constância mecânica, a constância física, a constância química..” (2000, tomo I, p. 117). Por conseguinte, o Direito tem uma função prático-política, é "fator constante de harmonia social". Pergunta Pontes de Miranda: "Que é o Direito?” Resposta: "É o que estabelece a solução nos conflitos da vida social.” (2000, t. I, p. 125).

O Direito tem uma função prático-política; é o fator essencial da ordem social. Como se pode enfatizar a importância dessa função prática e política do Direito e ao mesmo tempo afirmar que o Direito é um "fenômeno natural", como se os processos de adaptação social e as soluções de conflitos na vida social se realizassem sem a participação da ação humana?

Não parece fácil descobrir "empiricamente" o Direito na sociedade. Não é pela leitura de códigos e diários oficiais, mas Pontes de Miranda propõe outro "método" de descobrir o direito objetivamente real:

Sim: é ali que o haveis de encontrar, na vida social, um de cujos elementos é ele, e, se quereis vê-lo, provocai-o, feri-o, que não tardará o vejais no que ele tem de mais perceptível, que é a coerção, ou no que há de mais geral e revelador da solidariedade inerente aos corpos sociais: a garantia. (2000, t. I, p. 125)

Apresenta-se, de novo, uma comparação duvidosa, desta vez entre a força coercitiva do Direito e fenômenos verdadeiramente naturais, a eletricidade e o magnetismo. "Sob a forma de força o tendes [o Direito], e nisso assenta a segurança de sua objetividade. Não é mais objetiva do que ele a eletricidade, nem é ele menos suscetível de experimentação que os fenômenos magnéticos." (Pontes de Miranda, 2000, tomo I, p. 125).

Aqui Pontes de Miranda está errado. Sabe-se que em todos os sistemas sociais alguns delinquentes escapam da sanção jurídica; eletricidade e magnetismo, porém, são, de fato, fenômenos naturais, e suas energias manifestam-se como processos necessários e sem exceção. Isto é a diferença fundamental entre os fenômenos jurídicos e práticas sociais (que têm um caráter convencional, prescritivo, normativo) e os fenômenos verdadeiramente naturais, determinados por mecanismos universais e necessários. Não faz sentido atribuir aos fenômenos naturais e aos fenômenos culturais a mesma "objetividade".

Objeto de nossa crítica é o nivelamento da diferença entre fenômenos naturais e culturais, junto com a ideia de que se possa explicar e compreender, de modo exaustivo, os fenômenos culturais pelos métodos das ciências naturais. Tais métodos levam a abstrações - abstraindo, por exemplo, das atividades humanas -, de modo que não se esclarecem todos os pontos. Uma "sociologia compreensiva" no sentido de Max Weber poderia oferecer uma retificação. Até que ponto Pontes de Miranda estava familiarizado com a obra desse autor? Eis aí a concepção weberiana: 
[.... no caso das "formações sociais" (em oposição aos "organismos"), estamos em condições de realizar uma coisa que ultrapassa a simples constatação de conexões e regras ("leis") funcionais e que está eternamente negada a todas as "ciências naturais" (no sentido do estabelecimento de regras causais para processos e formação da "explicação" dos processos particulares a partir das regras): precisamente a "compreensão" das ações dos indivíduos nelas envolvidos, enquanto que, ao contrário, não podemos "compreender" o comportamento, por exemplo, das células, mas apenas registrá-lo funcionalmente e determiná-lo segundo as regras às quais está submetido. Esta vantagem da explicação interpretativa em face da explicação observadora tem, entretanto, seu preço: o caráter muito mais hipotético e fragmentário dos resultados obtidos pela interpretação. Mas, mesmo assim, esta constitui precisamente o ponto específico do conhecimento sociológico. (Weber, 1991, p. 10)

O contraste não poderia ser maior. É o contraste entre duas concepções antagônicas de Sociologia. Para um weberiano, a "Sociologia" de Pontes de Miranda seria pseudossociologia, pois nada contribui para elaborar conhecimentos especificamente sociológicos; um defensor de Pontes de Miranda consideraria a Sociologia de Max Weber como não científica. Conciliar ou sintetizar as duas concepções é impossível. Será que Pontes de Miranda optava pela "explicação observadora", porque não estava disposto a pagar o preço de se contentar com conhecimentos mais hipotéticos e fragmentários? No que concerne à concepção de "corpos sociais" em Miranda, prevalece, de fato, a impressão de que o comportamento dos indivíduos se reduz ao funcionamento de células do "organismo" social.

Pontes de Miranda utiliza também a linguagem organicista. Afirma, por exemplo: "Fenômeno natural, o direito é essencial à vida das sociedades, como, para o homem, o coração e os pulmões.” (2000, tomo I, p. 127). Também esta comparação é defeituosa. Sem o coração e os pulmões, o homem não sobrevive. Numa sociedade anárquica, em que o Direito como fator de ordem pública perdeu sua força, os indivíduos encontram-se constantemente em perigo de vida, mas a sobrevivência é possível: muitos vêm a ser vítimas de homicídio, outros se salvam e sobrevivem.

Não obstante, um argumento de Pontes de Miranda está correto. O Direito não é somente um sistema de ideias, um mero produto do espírito humano; é também - expressão de Hegel - "espírito objetivo", espírito que se realiza no mundo: a objetividade do Direito manifesta-se na sua eficiência como fator de ordem na vida social, e não na forma de códigos e decretos jurídicos. Contudo, deve-se distinguir esse tipo de "objetividade", que se refere aos fenômenos culturais, da objetividade dos fenômenos naturais, caracterizados pela universalidade. Não se pode simplesmente identificar "objetividade" e "universalidade", pois nem todos os fenômenos objetivamente reais têm a origem de sua existência ou ocorrência em forças ("leis") universais da natureza.

Obviamente, na concepção de Pontes de Miranda, a objetividade específica do Direito caracteriza-se pela sua força e eficácia como fator de estabilidade das relações sociais e da adaptação do homem à vida social. Surpreendente e pouco compreensível é 
o recurso às "leis biológicas" de adaptação, junto com a tese de que a função adaptadora do Direito deve ser analisado como "fato biológico" (2000, t. III, 134)․ Pontes de Miranda pensa poder constatar este tipo de eficácia do Direito como constante em todas as sociedades humanas. Dificilmente essa constância pode ser aceita como mais um critério da naturalidade do Direito. Pelo fato dessa constância não se pode refutar a tese de que os sistemas jurídicos são criações humanas. Quem compreende os sistemas jurídicos como invenções humanas pode explicar tais constâncias da seguinte maneira: os homens em todos os tempos e em todas as culturas enfrentam os mesmos problemas: são vulneráveis, mas frequentemente ameaçados pelas tendências antisociais de seus semelhantes; eles têm necessidade de proteção. Quando os problemas sempre e em toda a parte são os mesmos, então não é milagre algum que seres dotados dos mesmos talentos intelectuais criam soluções quase idênticas.

O que todas as ideias têm com o método intuitivo? Como se pode descobrir por meio da indução - por mera observação de fatos particulares e determinadas regularidades - a tese de que a adaptação social é um fenômeno natural, determinado por leis biológicas? Na verdade, neste raciocínio, a teoria biológica já está pressuposta: os fenômenos biológicos e sociais são interpretados à luz das "leis biológicas" de adaptação, cuja validade não se descobre pela análise dos fatos, mas explica sua causalidade.

Pontes de Miranda atribui demasiada importância ao método indutivo; além disso, muitos de seus conhecimentos, ideias e descobertas não se fundamentam no método indutivo. Reconhece, por exemplo, a superioridade da teoria de Einstein em comparação com a teoria newtoniana. (2000, t. I, p. 86 e ss.) Será que na comparação das duas teorias a utilização do método indutivo levou Pontes de Miranda a dar preferência à teoria de Einstein? E, se, de fato, o método indutivo for o método único, exclusivo da pesquisa científica, será que Einstein simplesmente era mais hábil do que Newton na aplicação desse método?

De fato, a teoria de Einstein não é fruto do método indutivo; ao contrário, Einstein defendeu o método dedutivo e se distanciou do método indutivo.

\section{PROBLEMAS DO MÉTODO INDUTIVO}

Pontes de Miranda estava muito bem familiarizado com a Teoria da Relatividade, sobre a qual até escreveu um artigo. Essa teoria não podia ser o resultado de uma pesquisa indutivo-experimental. Estranho que ele não percebeu isto. Conheceu

\footnotetext{
${ }^{1}$ Cf. a mesma obra, tomo III, p. 60: "se estudarmos, através de todos os tempos e com o auxílio da biologia, o fenômeno jurídico, veremos que ele apenas continua o processo de harmonização.”
} 
Einstein pessoalmente e, com certeza, soube de sua viagem à América do Sul em 1925, e provavelmente também do comentário que no Rio de Janeiro fez ao jornalista Assis Chateaubriand: "O problema que minha mente formulou foi respondido pelo luminoso céu do Brasil", referindo-se a uma observação do eclipse solar de 29 de maio de 1919 registrado na cidade cearense de Sobral (Will, 1996, p. 76). Uma equipe de astrônomos tirou fotografias do Sol obscurecido e do campo estrelar circundante. O mesmo campo estrelar foi fotografado antes, durante e depois do eclipse. Pela comparação das fotografias puderam confirmar a deflexão da luz prevista por Einstein. A Teoria da Relatividade, até agora mera especulação, foi corroborada por esta observação. Por conseguinte, não foi uma observação empírica pela qual a teoria se originou; ao contrário, a teoria não era nada mais do que uma hipótese ousada cuja veracidade estava incerta.

Num ensaio de 1919 intitulado "Induktion und Deduktion in der Physik", Einstein compara os dois métodos e, concernente ao método indutivo, afirma: "[....] os grandes avanços do conhecimento científico originaram-se dessa forma apenas em pequena escala." Depois descreve sua preferência pelo método dedutivo:

Os avanços verdadeiramente grandes em nossa compreensão do mundo se originaram de um modo quase diametralmente oposto à indução. $\mathrm{O}$ domínio intuitivo do essencial de um enorme complexo de fatos leva o cientista a postular uma ou mais leis hipotéticas básicas. Dessas leis ele tira suas conclusões. (1919 apud Isaacson, 2007, p.135)

No mesmo sentido pronunciou-se no seu livro C omo Vejo o M undo:

A suprema tarefa do físico consiste, então, em procurar as leis elementares mais ge-
rais, a partir das quais, por pura dedução, se adquire a imagem do mundo. Nenhum
caminho lógico leva a tais leis elementares. Seria antes exclusivamente uma intuição
a se desenvolver paralelamente à experiência. (1981, p. 140)

As grandes descobertas de Einstein, que revolucionaram a Física, não se iniciaram em descobertas empíricas, mas na análise crítica de discrepâncias causadas por teorias conflitantes e na percepção de problemas ainda não resolvidos pela teoria física de sua época.

Neste artigo, não é possível examinar os problemas do método indutivo na sua totalidade; nem se podem pormenorizar os vários tipos de indução. Estão em jogo exclusivamente os problemas do método indutivo baconiano tal como este foi repristinado e utilizado por Pontes de Miranda no seu Sistema da Ciência Positiva do Direito. Trata-se de uma indução ampliativa, isto é, o raciocínio usado consiste em passar de fatos particulares a uma lei geral, ou, de modo mais sofisticado, em selecionar e agrupar observações particulares de maneira que as leis que conectam os fenômenos observados se evidenciem. Na argumentação indutiva deste gênero, sempre algo que está além do conteúdo das premissas é apoiado nelas; por isso, não é uma inferência válida. Da premissa "alguns a são b" não se pode concluir que "todos os a são b". Na 
"conclusão" desse gênero aquele "algo" que ultrapassa o conteúdo das premissas - a generalização ou a "lei geral" - verifica-se só como provável em maior ou menor grau, pois o grau de probabilidade depende das evidências inicialmente selecionadas a seu favor. Se, por exemplo, passo da observação de que "alguns homens têm pés chatos" (= evidência inicial) à conclusão "todos os homens têm pés chatos", desta forma apresentase uma inferência cujo grau de probabilidade é menor do que no caso de se apoiar o enunciado "todos os homens têm dois braços" na premissa de alguns (ou muitos) terem dois braços. Conclusões indutivas passam de estados de coisas mais específicos aos mais gerais ou da espécie ao gênero. Não tudo que está certo nos casos específicos também está nos casos mais gerais. Do ponto de vista puramente lógico, a inferência indutiva é insustentável. Do ponto de vista empírico, é duvidosa.

Mesmo se se pretende utilizar tais inferências como raciocínios meramente prováveis, - o que poderia ser a concepção de um empirismo bastante modesto - ainda há um problema que pelo princípio de indução não se soluciona, isto é, a questão de saber como é possível descobrir as adequadas evidências particulares para que a conclusão daí extraída corresponda à realidade. Não se pode realizar tal descoberta empregando o método indutivo. Também na perspectiva heurística, utilizando o método indutivo como instrumento para fazer descobertas, isto é, elaborar novos conhecimentos, a indução implica um fundamento extralógico e - obviamente - extraindutivo: a crença na ordem universal e na lei da uniformidade da natureza assim como no princípio de que as mesmas causas produzem os mesmos efeitos. Para explicar a natureza, o pesquisador que se apoia na indução utiliza (sem se dar conta?) hipóteses que indutivamente não se justificam, e isto mostra que para a pesquisa científica o método indutivo não pode ser o único método.

Do princípio da uniformidade da natureza Pontes de Miranda faz uso exagerado, combinando esse princípio com a ideia da objetividade do Direito. O Direito, como fenômeno objetivo, como fato mundano, é, como afirma Pontes de Miranda, mudança no mundo.

O mundo compõe-se de fatos, em que novos fatos se dão. O mundo jurídico compõe-se de fatos jurídicos. Os fatos, que se passam no mundo jurídico, passam-se no mundo, portanto: são. O mundo não é mais do que o total dos fatos e, se excluíssemos os fatos jurídicos, que tecem, de si mesmos, o mundo jurídico, o mundo não seria a totalidade dos fatos. (2000, tomo II, p. 286)

A realidade mundana do Direito está fora de questão. Um jurista que defende a objetividade do Direito enquanto fator de estabilidade social na sociedade evidentemente está autorizado a incluir o Direito na totalidade dos fatos. No entanto, deve-se levar em consideração a diferença das perspectivas: por um lado, a perspectiva do físico, por outro, a visão do jurista. Quando o físico ou o astrônomo fala do universo (no sentido 
de conjunto das coisas), esse conceito não é tão universal como parece, porque nesta perspectiva as instituições culturais simplesmente não são examinadas. Por isso, não se deve esquecer as diferenças fundamentais entre o mundo natural - tema das ciências naturais - e o mundo cultural, do qual o direito enquanto instituição político-social e a disciplina acadêmica do Direito fazem parte. Os novos fatos que o Direito cria no mundo têm estruturas específicas que não se encontram no mundo natural e não se compreendem na sua especificidade pelos métodos dos naturalistas. Quando os "fatos jurídicos" - impregnados por várias culturas e diversos nas diferentes culturas - se passam no mundo (entram no mundo), deste modo entram estruturas pluralistas no "total dos fatos". Quando o jurista, a saber, Pontes de Miranda, elabora um conceito mais abrangente de "total dos fatos" do que os físicos, incluindo neste universo o mundo jurídico, não se podem negligenciar as diferenças estruturais entre os dois mundos, o mundo natural e o mundo do Direito. Penso que, para uma concepção diferenciada, Max Weber (não Pontes de Miranda) indicou o caminho certo.

\section{CONCLUSÃO}

No futuro, não abandonarei o estudo da Teoria do Direito de Pontes de Miranda, pois a obra dele é rica de ideias interessantes e estimulantes. No entanto, minha leitura até agora realizada - infelizmente de curto prazo - não me motivou a corrigir a minha posição. Como dantes, penso que o mundo cultural, do qual o Direito faz parte, na sua especificidade não pode ser exaustivamente compreendido pelos métodos das ciências naturais. Em contraposição com Pontes de Miranda concordo com a posição de Einstein: as grandes descobertas da Física se originaram não no método indutivo, mas pela elaboração de hipóteses ousadas. Para a ciência, teorias e métodos não são objetos sagrados, mas simplesmente instrumentos na procura da verdade e de soluções de problemas. Por Max Weber sinto-me confirmado na convicção de que, nas disciplinas da Ética e do Direito, as discordâncias normativas e os litígios não podem ser resolvidos com a mesma pretensão de objetividade como se solucionam, a longo prazo, as discrepâncias teóricas na Física, Astronomia, Química e Biologia.

\section{REFERÊNCIAS}

EINSTEIN, Albert. Como vejo o mundo. Rio de Janeiro: Nova Fronteira, 1981.

ISAACSON, Walter. Einstein. Sua vida, seu universo. 2. reimpr. São Paulo: Companhia das Letras, 2007.

MALUSCHKE, Günther. A bioética e o biodireito: aspectos e controvérsias. Revista Jurídica da Fa7, v. VI, n 1, p. 53-64, abr. 09. 
PINTO, Agerson Tabosa. Sociologia Geral eJurídica. Fortaleza: Qualygraf, 2005. PONTES DE MIRANDA. Sistema de Ciência Positiva do Direito. V. I - IV. Campinas: Bookseller, 2000.

Introdução à Política Cientúfica. Rio de Janeiro: Forense, 1983.

WEBER, Max. Economia eSociedade, Fundamentos da Sociologia Compreensiva. Brasília: UnB, 1991.

WILL, Clifford M. Einstein Estava Certo? Colocando a Relatividade Geral à prova. Brasília: UnB, 1996.

\section{IS LAW ANAT URAL PHENOMENON? ACRITIQUE OF THE VIEWPOINT OF PONTESDE MIRANDA}

Abstract: This article is a critical review of the thesis of the "Naturalness of the Juridical Phenomenon" by Pontes de Miranda and a refutation of the inductive method defended by this author, but not accepted by Einstein as the adequate method of science. Against the scientism of Pontes de Miranda we intend to defend the superiority of a "comprehensive sociology" in the sense of Max Weber.

Keywords: Nature. Naturalness. Scientism. Inductive method. Comprehensive sociology. 